\title{
Assessment of the Level of Some Selected Heavy Metals and Physicochemical in Abzana Water Samples, Kibet Woreda, Ethiopia
}

Tolesa Tesfaye ( $\nabla$ tolesatesfaye55@gmail.com )

Werabe university https://orcid.org/0000-0001-5154-3089

Haregot Tesfau

U1 University

Adigi Balcha

Werabe University

Muktar Hassen

Werabe University

\section{Research}

Keywords: Drinking water, Heavy metals, ICP-OES, Physico-chemical parameters, WHO

Posted Date: July 22nd, 2021

DOI: https://doi.org/10.21203/rs.3.rs-696893/v1

License: (9) This work is licensed under a Creative Commons Attribution 4.0 International License. Read Full License 


\section{Abstract}

Background: This study was conducted to investigate the contamination level of Abzana water in Asano district. A total of five water samples were collected from different point of Abzana water. Some parameters of water were analyzed like temperature, $\mathrm{pH}$, electrical conductance and total dissolved solids (TDS) and four heavy metal ( $\mathrm{Cd}, \mathrm{Pb}, \mathrm{Cr}$, and $\mathrm{Mn}$ ) concentration using standard procedures and the results were compared with $\mathrm{WHO}$ guideline values.

Result: The results of the present study have shown the temperatures of all sampling station range between 18.9 and $19.2^{\circ} \mathrm{C}$. The $\mathrm{pH}$ was found to be of range from 6.54 to 7.11 whereas, the electrical conductance was 174.5 to $206(\mu \mathrm{S} / \mathrm{cm})$. In addition, the lowest value of TDS was 131.4 and the highest was $140.1 \mathrm{ppm}$. In contrast, heavy metals ( $\mathrm{Pb}, \mathrm{Cd}, \mathrm{Cr}$ and $\mathrm{Mn}$ ) were analyzed and compared with standards of drinking water. The results indicate that the mean concentration of $\mathrm{Cd}(0.00664 \mathrm{mg} / \mathrm{l})$ exceeded the standards, although the mean concentration of $\mathrm{Mn}, \mathrm{Pb}$ and $\mathrm{Cr}$ were found within the standard limit at $0.076082,0.00810$ and $0.035442 \mathrm{mg} / \mathrm{l}$ respectively.

Conclusion: The concentrations of the investigated metal ( $\mathrm{Cr}, \mathrm{Pb}$ and $\mathrm{Mn})$ and all physico-chemical result of Abzana water from Asano kebele were found below the guidelines for drinking water given by the World Health Organization. But the concentration of $\mathrm{Cd}$ in Abzana water sample was found above the permissible limit of WHO standards. Therefore, it was not safe for drinking and health effect according metals what we have studied here.

\section{Introduction}

Water plays an important role in the world economy, as it functions as a universal solvent, which has the ability to dissolve many substances of organic or inorganic compounds, industrial cooling and transportation (Bernard and Ayeni 2012). Water is obtained from a variety of sources like; wells, stream, rivers, lakes, reservoirs and etc. are supporting drinking water supply, livestock needs, irrigation, industrial and many other commercial and domestic purposes (Zinabu et al. 2015). The quality of these water source may be affected by; a rise in anthropogenic activities, a raise in population, urbanization, global climate change and any pollutant either physical or chemical (Aremu et al. 2011). Chemical contaminants of water mainly consist of heavy metals, fertilizers and thousands of toxic organic compounds (Jackson et al. 2001). Metal pollution can result from direct atmospheric deposition, geologic weathering or through the discharge of agricultural, municipal or industrial waste products (Dugasa and Endale 2018). Heavy metals in water occur only in trace levels but are damaged central nervous function, blood irregularity and also badly effect vital organs such as kidneys and liver (Baroni et al. 2007).

In developing countries, like Ethiopia, have suffered from a lack of access to safe drinking water from improved sources and to adequate sanitation services (WHO 2006). As a result, people are still dependent on unprotected water sources such as rivers, streams, springs and hand dug wells. Since these sources are open, they are highly susceptible to flood and birds, animals and human contamination (Messeret 
2012; Gebrekidan and Samuel 2011). Over $60 \%$ of the communicable diseases in Ethiopia are due to poor environmental health conditions arising from unsafe and inadequate water supply and poor hygienic and sanitation practices ( $\mathrm{MOH} 2011)$.

In Ethiopia, much research has been carried out with regards to assessment of heavy metal concentrations in different river and lakes like: Hawassa and Ziway (Kiflom and Tarekegn 2015), Lake Baseka (Fuad and Gelaneh 2017), Rebu river in oromia region (Mekonnen 2018), Abaya and Chamo Lakes (Dugasa and Endale 2018), Chilga drinking water (Tsegu et al. 2015), All these findings give conclusive evidence that water quality problems are rampant both with small-scale and large-scale water delivery systems in the country. This may pose high health risks to users unless prompt intervention is undertaken. Abzana is also one of the stream water located in Kibet woreda Asano district and often used as a drinking and other domestic activities for the people of Asano district. There is no study that was conducted to prove the quality of Abzana water before. Therefore, the present study was conducted on Abzana water to check the quality and generate baseline data for further studies

\section{Materials And Methods}

\section{The study area}

The study was conducted in Kibet woreda Asano kebele, which was located in $30 \mathrm{~km}$ north direction from the town of Worabe and about $150 \mathrm{~km}$ south of Addis Ababa, Ethiopia's capital city. Abzana stream water is located in Kibet woreda Asano kebele. The people around Asano use Abzana water for farmlands, drink, other domestic activities etc. The areas are under continuous cultivation throughout the year and have been supplying significant portion of a wide variety of vegetables.

\section{Apparatus and Chemicals}

Apparatus such as; different size beakers, measuring cylinders, volumetric flasks, burettes, funnel, test tubes, hydrometer, thermometer, oven, electronic-mill, plastic bags, stirrer, Erlenmeyer flask (different sizes), refrigerator, filter paper are used. All chemicals of high purity analytical grade reagents were employed; $69 \% \mathrm{HNO}_{3}$ and $\mathrm{HCl}(35-38 \%)$ were used for both extraction and acid digestion procedures. Distilled water used for preparation of stock standards of and intermediate standard solutions of $\mathrm{Mn}, \mathrm{Cr}$, $\mathrm{Cd}$ and $\mathrm{Pb}$ metals.

\section{Instrumentation}

Digital analytical balance used for all measurements of samples and chemicals, Inductively Coupled Plasma Optical Emission Spectroscopy (ICP-OES) was used to determine the concentrations of $\mathrm{Mn}, \mathrm{Cr}, \mathrm{Cd}$ and $\mathrm{Pb}$. Thermometer, digital $\mathrm{pH}$ meter, Conductivity meter and TDS meter was used to measure the temperature, $\mathrm{pH}$, electrical conductivity and total dissolved solid of the water sample respectively.

\section{Sample collection}


The present study was carried out at five sampling stations on Abzana stream water. Sampling sites for water were selected purposely which represents the entire water bodies having ecological significance. To avoid any kind of contamination during sampling extra care was taken and the bottles were rinsed several times with the water being collected or filled. The bottles were filled and then sealed tightly to avoid headspace that causes loss of samples because of oxidation. However, on-site analyses was comprised for temperature, electrical conductivity (EC), $\mathrm{pH}$ and TDS were urgently determined when receive the sample in the laboratory because of their unstable nature. All analyses were carried out at a standardized laboratory using international regulatory methods.

\section{Water sample digestion}

$100 \mathrm{ml}$ of the water sample was measured with a measuring cylinder and $5 \mathrm{ml}$ of concentrated hydrochloric acid was added to it. The solution was then transferred into a conical flask and a few boiling chips were added into the flask and heated on the hot plate for one hours at $95^{\circ} \mathrm{C}$ to $50 \mathrm{ml}$. Digestion is complete as shown by a light colour clear solution. It was then transferred into $100 \mathrm{ml}$ volumetric flask and distilled water was added to fill up to the mark where it was filtered and transferred into the precleaned sample bottle and taken for further Inductively Coupled Plasma Optical Emission Spectroscopy (ICP-OES) analysis.

\section{Heavy metal analysis}

A total of four trace elements were analyzed from the diluted digests of water samples using Inductively Coupled Plasma Optical Emission Spectroscopy (ARCOS FHS12) using aqueous calibration standards prepared from stock standard solutions of the respective elements. The instrument parameters optimized according to the manufacturers was provided. Finally, the data was statistically analyzed using Excel 2007 and Origin 8.1 software.

\section{Result And Discesion}

\section{Calibration of the instrument}

Calibration of the instrument (ARCOS FHS12) was done by the standards prepared before the determinations were done. Because the qualities of results obtained for heavy metals analysis using ICPOES are seriously affected by the calibration and standard solution preparation procedures. Calibration curves of the metals ( $\mathrm{Cd}, \mathrm{Pb}, \mathrm{Cr}$ and $\mathrm{Mn}$ ), were plotted and validated with their corresponding $\mathrm{R}^{2}$ values for the determination of each metal (Fig. 1). The correlation coefficients of all metals are higher than 0.999 , indicating good relationship between concentration and intensity in the range. The values of $R^{2}$ of the curves were $0.99996,0.99979,0.99936$ and 099967 for $\mathrm{Cd}, \mathrm{Pb}, \mathrm{Cr}$ and $\mathrm{Mn}$ respectively. The respective calibration curve was given in Fig. 1(A-D).

\section{Physicochemical Analysis}




\section{Temperature}

Temperature is a basic water quality variable. It determines the suitability of water for various forms of aquatic life (Chirag 2017). Cool water is generally more usable than hot water, and temperature will impact on the acceptability of a number of other inorganic constituents and chemical contaminants that may affect taste. High water temperature increases the growth of microorganisms and may increase taste, odour, colour and corrosion problems (WHO 2011).

The temperature $\left({ }^{\circ} \mathrm{C}\right.$.) of all sample station was shown in Fig. 2 . The temperatures of all sampling station range between 18.9 and $19.2^{\circ} \mathrm{C}$ (Table 3 ). As indicated in graph below, the temperature was 19.1, 18.9, $19.2,19$ and $19.2^{\circ} \mathrm{C}$ in sample $1,2,3,4$ and 5 respectively. The World Health Organization (WHO) guidelines recommend a maximum temperature limit of $25^{\circ} \mathrm{C}$ in the domestic drinking water. The average temperature in this study was $19.08^{\circ} \mathrm{C}$, which was found within permissible limit of WHO standards.

\section{Hydrogen lon Concentration $(\mathrm{pH})$}

$\mathrm{pH}$ of water is a measure of amount of hydrogen ions that is present in the water. We measure the $\mathrm{pH}$ of the water to determine wither the water is alkaline or acidic in nature. The $\mathrm{pH}$ scale is logarithmic and ranges from 0 (very acidic) to 14 (very alkaline). The permissible value of $\mathrm{pH}$ for drink water is 6.5 to 8.5 (WHO 2017). The result of pH was shown in Fig. 3. The maximum pH of 7.11 was reported in sample 2, and the least $\mathrm{pH}$ of 6.54 was reported in sample 4 . Acidic nature of sample 4 may result from carbonic acid deposit formed via reaction of carbon dioxide with rainwater. On the other hand, there are a large number of plants growing around these three sampling station, they release carbon dioxide when they die and decompose. When the $\mathrm{CO}_{2}$ mixes with the water, a weak carbonic acid is formed; this can then cause the $\mathrm{pH}$ of the water body to decrease.

Slightly alkalinity of water in sample 2 may be attributed to the presence of bicarbonates into the soil and percolated into the water by runoff. In addition, biological degradation of waste in the soil may be a major influence of this observation. The mean Hydrogen Ion Concentration in Abzana water was found to be 6.86 and it is within the desired limit of WHO standards.

\section{Electrical conductivity (EC)}

The electrical conductivity (EC) can be defined as it is a numerical expression that shows the ability of water to hold an electrical current and it is related to ionic forces of the solution and the number of salts dissolved in water (Algamal 2015). Electrical conductivity is used to indicate the total ionisable constituents of water. It is directly related to sum of the cations and anions. As most of the salts in water are present in ionic forms, they make water capable for conducting current (Adhena et al. 2015). According to WHO standards, EC valueshould not exceeded $400 \mu \mathrm{S} / \mathrm{cm}$ (WHO, 2011).

The experimental analysis for electrical conductivity $(E C)$ was carried out for all samples. The result was shown in Fig. 4 above. The EC of all Abzana water samples is varied between $174.5 \mu \mathrm{S} / \mathrm{cm}$ to $206 \mu \mathrm{S} / \mathrm{cm}$. 
This is in the range of WHO standards. The high value of EC in sample $4(206 \mu \mathrm{S} / \mathrm{cm})$ indicates the presence of a high amount of dissolved inorganic substances in the ionized form at that location. The average value of EC in Abzana water was $191.3 \mu \mathrm{S} / \mathrm{cm}$. The overall result indicates that the water samples in all sampling station of Abzana are within the desirable and suitable range.

\section{Total dissolved solid (TDS)}

Total dissolved solids (TDS) are the term used to describe the inorganic salts and small amounts of organic matter present in solution in water. The water with high TDS value indicates that water is highly mineralized. The TDS result in present study was shown in Fig.5. Desirable limit for TDS is $500 \mathrm{mg} / \mathrm{l}$ and maximum limit is $1000 \mathrm{mg} / \mathrm{l}$ prescribed for drinking purpose (WHO, 2017).

As shown in Fig. 5 above, the total dissolved solids concentration for all samples in present study was observed in the range of 131.4 and $140.1 \mathrm{ppm}$. The highest TDS values of $140.1 \mathrm{ppm}$ and the lowest TDS values of $131.4 \mathrm{ppm}$ correspond to samples 4 and sample 1, respectively. The highest TDS value in sample 4 shows the existence of inorganic salts and organic matter and the reason is due to sewage and urban and agricultural run-off. Water containing high total dissolved solid may cause laxative or constipation effects. Potable water should not contain more than $500 \mathrm{ppm}$ of total dissolved solids (TDS) (Sasikaran et al. 2012). The average TDS value of Abzana water was 136.74 ppm which was found within the safe limit of WHO-standards.

\section{Heavy metal analysis}

The amount of heavy metal micro contaminants in five water samples was analysed with Inductively Coupled Plasma Optical Emission Spectroscopy (ICP-OES). Four heavy metals like cadmium (Cd), lead $(\mathrm{Pb})$, chromium $(\mathrm{Cr})$ and manganese $(\mathrm{Mn})$ were observed in all five sampling station.

\section{Cadmium}

Cadmium is highly toxic non-essential heavy metal and it does not have a role in the biological process in living organisms. Thus even low concentration, Cadmium could be harmful to living organisms ( Ambedkar and Muniyan 2012). The permissible value of cadmium concentration for drink water is 0.003mg/L (WHO 2017).

Cadmium was reported in water samples of all sampling stations. As shown in Fig. 6, the concentration of Cadmium is varied from 0.00557 to $0.00712 \mathrm{mg} / \mathrm{L}$. High concentration of Cadmium in sample point 4 and 5 which was 0.00712 , and $0.00701 \mathrm{mg} / \mathrm{L}$ respectively, may be due to the increase mixing of agricultural runoff from agricultural fields to Abzana. The cultivated areas are more concentrated around these two sampling point. Therefore, the increasing consumption of pesticides and herbicides and chemical fertilizers in addition to soil contamination transfer these materials by water irrigation or rainfall (runoff) resulting in the contamination of adjacent surface water (Abzana). The mean concentration of Cadmium in Abzana water sample was $0.00664 \mathrm{mg} / \mathrm{L}$. The result shows the concentrations of Cadmium 
in all samples are higher than the recommended value of drinking water by WHO. Therefore, the quality Abzana water is not recommended for drinking due to heavy Cadmium stress.

\section{Lead}

Lead serves no useful purpose in the human body. Even though Lead does not dissolve easily into the environment, it can mix with soil particles or dust and enter underground water or drinking water following rain and surface water runoff. Exposure of Lead can occur when eating food cultivated on soil with high Lead concentrations, drinking contaminated water, breathing polluted air and so on (AbdulWahab et al. 2012). The permissible value of Lead concentration in drink water is $0.01 \mathrm{mg} / \mathrm{L}(\mathrm{WHO}, 2017)$

As shown on Fig. 6, the concentration of Lead in water of all five sampling stations ranged between $0.00761 \mathrm{mg} / \mathrm{L}$ to $0.00854 \mathrm{mg} / \mathrm{L}$. The concentration of Lead in station four $(0.00854 \mathrm{mg} / \mathrm{L})$ was high compared to other sampling station. Slightly high concentration of Lead in station 4 is may be due to disintegration/breakdown and leaching of Lead from Abzana mountain rocks dumps. The mean Lead concentration in Abzana water was $0.008098 \mathrm{mg} / \mathrm{L}$. Thus, the overall result indicates that, in the Abzana stream water Lead content are within the permissible limit. So the level of Lead obtained in the present study does not indicate a potential health hazard to consumers.

\section{Chromium}

Chromium is an essential trace nutrient that is required in small amounts for carbohydrate metabolism, but becomes toxic at higher concentrations. The permissible value of chromium concentration for drink water is $0.05 \mathrm{mg} / \mathrm{L}(\mathrm{WHO}, 2017)$.

As shown in Fig. 6 above, Chromium was observed in all Abzana sampling station. The concentrations of Chromium were found between $0.02642 \mathrm{mg} / \mathrm{L}$ and $0.04240 \mathrm{mg} / \mathrm{L}$. High concentration of chromium was observed in sampling station 3 and 5. Slightly high concentration of Chromium in station 3 and 5 may be due to the sensitivity of the site for runoff and human activities. The mean concentration of Chromium in this study was $0.03544 \mathrm{mg} / \mathrm{L}$. This value is lower than the maximum permissible limit of Chromium concentration recommended for dinking purpose.

\section{Manganese}

Manganese is essential trace element required for various biochemical processes. The kidney and liver are the main storage places for the Manganese in the body. Manganese is essential for the normal bone structure, reproduction and normal functioning of the central nervous system. Its deficiency causes reproductive failure in both male and female (Saraf and Samant 2013). The permissible value of Manganese concentration for drink water is $0.1 \mathrm{mg} / \mathrm{L}$ (WHO 2017).

As shown on Fig. 6 above, the concentration of Manganese over the surface of Abzana water varies between $0.06126 \mathrm{mg} / \mathrm{L}$ and $0.09053 \mathrm{mg} / \mathrm{L}$. However, higher concentration of Manganese was recorded in sampling station 3 and 5 which was $0.08513 \mathrm{mg} / \mathrm{L}$ and $0.09053 \mathrm{mg} / \mathrm{L}$ respectively, indicating that the 
sites are highly polluted areas. High amounts of Manganese in these two sampling sites is may be due to dumping of dead organisms, aquaculture input, low level of water, plant life and animals. The arithmetic average concentration of Manganese obtained from Abzana water sample was $0.076082 \mathrm{mg} / \mathrm{L}$ and it was higher than the permissible value of WHO standards for drinking purpose. The increments in the concentration were due to the effects of natural and human activities diluted by hot springs bulk waters. Manganese concentration in water may be toxic to a number of crops at a few-tenths, it's above permissible limit was $0.2 \mathrm{mg} / \mathrm{L}$ for long term irrigation as well as available for livestock (Tamiru 2005). In general, the concentration of Manganese was found below the permissible level in all water sample of Abzana and the water quality is safe for drinking and other activities

\section{Conclusions}

The main goal of this paper was to assess the status of Abzana water quality in Asano located southern Ethiopia, with special emphasis on trace heavy metals and physico-chemical analysis. A total of five water samples were collected from Abzana stream water. All of the samples were analyzed for four heavy metals ( $\mathrm{Cd}, \mathrm{Pb}, \mathrm{Cr} \& \mathrm{Mn}$,) and physico-chemical (temperature, $\mathrm{pH}, \mathrm{EC}$ and TDS) using standard procedures. The results of the samples vary among the samples because of the anthropogenic factors like disposal of effluent from the municipals and natural processes such as precipitation inputs, erosion, weathering of crustal materials, dilutions of rocks by hot ground waters, etc. The concentrations of the investigated metal ( $\mathrm{Cr}, \mathrm{Pb}$ and $\mathrm{Mn}$ ) and all physico-chemical result of Abzana water from Asano kebele were found below the guidelines for drinking water given by the World Health Organization. But the concentration of $\mathrm{Cd}$ in Abzana water sample was found above the permissible limit of WHO standards. Therefore, it was not safe for drinking and health effect according metals what we have studied here. To ensure that public health is better protected, future study is needed on: effects of multiple heavy metals on human health and removal of heavy metals and on other physical, chemical and biological parameters of significant health concern and on identification of potential sources of the contaminants.

\section{Declarations}

\section{Acknowledgements}

We want to thank Werabe University for provided financial support for field data collection and water laboratory analysis.

Furthermore, we are grateful to Horticoop Ethiopia (Horticulture) PLC, for support in analyzing of heavy metal contamination of Abzana water samples using Inductively Coupled Plasma Optical Emission Spectroscopy (ICP-OES)

\section{Authors' contributions}

TT (main author) collected, analyzed, and interpreted the data and wrote the manuscript. HT, MH and AB edited, commented, and suggested ideas in the manuscript preparation process. All authors read and 
approved the final manuscript.

Availability of data and materials: All data and materials used in the study are presented in the main paper.

\section{Declarations Ethics approval and consent to participate}

The research entitled "Assessment of the level of some selected heavy metals and physicochemical in Abzana water samples" is our own work that has be conducted under the supervision of the university research directorate and research committee. We followed all the ethical principles of scholarship in the preparation, data collection, data analysis and completion of this research. All scholarly matter that is included in the project was given recognition through citation. We adequately cited and referenced all the original sources. We also declare that we have adhered to all principles of academic honesty and integrity and we have not misrepresented, fabricated, or falsified any idea / data / fact / source in my submission. We further declare that this research has not been submitted to any other organization and journal.

Competing interests: The authors declare that they have no competing interests.

Consent for publication: not applicable

Funding: this research paper has been funded by Werabe University (WRU)

Author details: ${ }^{1}$ Department of chemistry, Werabe University (WRU), Werabe Ethiopia.

Email: tolesatesfaye55@gmail.com. 2Department of chemistry, Werabe University (WRU), Werabe Ethiopia. Email: haregotte@gmail.com. ${ }^{3}$ Department of mathematics, Werabe University (WRU), Werabe Ethiopia. ${ }^{4}$ Department of chemistry, Werabe University (WRU), Werabe Ethiopia.

\section{References}

1. Abdul-Wahab, S.; Marikar, F. (2012). The environmental impact of gold mines: Pollution by heavy metals. Open Eng , 2, 304-313.

2. Adhena Ayaliew Werkneh, Belay Zimbelachew Medhanit, Angaw Kelemework Abay, Jemal Yimer Damte. (2015). Physico-chemical analysis of drinking water quality at Jigjiga City, Ethiopia. American Journal of Environmental Protection , 4 (1), 29-32.

3. Algamal, Y. (2015). Assessment and statistical study of physico-chemical properties of water quality in some local water treatment plants in Jeddah,Kingdom of Saudi Arabia. Advances in Applied Science Research , 6 (7), 49-56.

4. Ambedkar G. and Muniyan M. (2012). Analysis of heavy metals in water,sediments and selected freshwater fish collected from Gadilam river. indian international journal of toxicol.appl.phamacol. , 2 (2), 25-30. 
5. Aremu MO et al (2011) Physicochemical characteristics of stream, well and borehole water sources in Eggon, Nasarawa State, Nigeria. J Chem Soc.Nigeria 36(1):131-136

6. Baroni, L.Cenci, and M. Berati. (2007). Evaluating the environmental impact of various dietary pattern combined with different food production systems. Europ. J. of Clinical Nutr. , 61, 279-286.

7. Bernard E, Ayeni N. (2012). Physicochemical analysis of groundwater samples of Bichi Local Government Area of Kano State of Nigeria. . World Environ , 2 (6), 116-119.

8. Chirag Ramesh Shah. (2017). Which Physical, Chemical and Biological Parameters of water determine its quality? OLID LIQUID RESOURCE MANAGEMENT IN SMART CITIES .

9. Dugasa Gerenfes and Endale Teju. (2018). Determination of Some Selected Heavy Metals in Water,Oreochromis niloticus and Labeobarbus intermedius Samples from Abaya and Chamo Lakes. Journal of Natural Sciences Research , 8 (21), 85-95.

10. Fuad Abduro and Gelaneh W/michael. (2017). Determination of heavy metals concentrations within the ever growing Lake Baseka, Ethiopia using spectrophotometric technique. Afr. J. Environ. Sci. Technol. , 11 (3), 146-150.

11. Gebrekidan M, Samuel Z. (2011). Concentration of heavy metals in drinking water from urban areas of the Tigray Region, Northern Ethiopia. Coll Nat ComputSciMekelleUni , 3 (1), 105-121.

12. Jackson et al (2001) Water in changing world, Issues in Ecology. Ecol Soc Am, Washington, pp 1-16

13. Kiflom Gebremedhin and Tarekegn Berhanu. (2015). Determination of Some Selected Heavy Metals in Fish and Water Samples from Hawassa and Ziway Lakes. Science Journal of Analytical Chemistry , $3(1), 10-16$.

14. Mekonnen Tadesse, D. T. (2018). Assessment of the level of some physico-chemical parameters and heavy metals of Rebu river in oromia region, Ethiopia. J His Arch \& Anthropol Sci , 3 (3), 146-150.

15. Messeret $B$ (2012) Assessment of drinking water quality and determinants of household potable water consumption in Simada district, ethiopia

16. $\mathrm{MOH}$ (2011) Knowledge, attitude and practice of water supply, environmental sanitation and hygiene practice in selected worked as of Ethiopia

17. Sasikaran, K Sritharan, S Balakumar, V Arasaratnam. (2012). Physical, chemical and microbial analysis of bottled drinking water. Ceylon Medical Journal , 57 (3), 111-116.

18. Saraf A, Samant A. (2013). Evaluation of some minerals and trace elements in Achyranthes aspera Linn. Int. J. Pharma. Sci. , 3 (3), 229-233.

19. Tamiru A. (2005). Hydro geochemical and lake level changes in Ethiopia Rift. . Elsevier: J. Hydrol.pp. , $1-11$.

20. Tsegu Lijalem, Arul Jeevan, Tariku Bekele, and Abrha Berhe. (2015). Determination of Some Essential and Toxic Metals in Low Grade Coal and drinking , Amhara region. International Journal of Innovation and Scientific Research , 17 (2), 412-422.

21. World Health Organization (2006) In water, sanitation and health world health organization

22. WHO. (2011). Guidelines for drinking-water quality (4th ed ed.). World Health Organization. 
23. WHO. (2017). Guideline for drinking-water Quality (4th Edition incorporating the frst addendum ed.). Switzerland.

24. ZinabuAssefaAlemu*,KirubelTesfayeTeklu, TsigeredaAssefaAlemayehu, KifleHabte Balcha and SisayDersoMengesha. (2015). Physicochemical quality of drinking water sources in Ethiopia and its health impact. Environmental Systems Research .

\section{Figures}
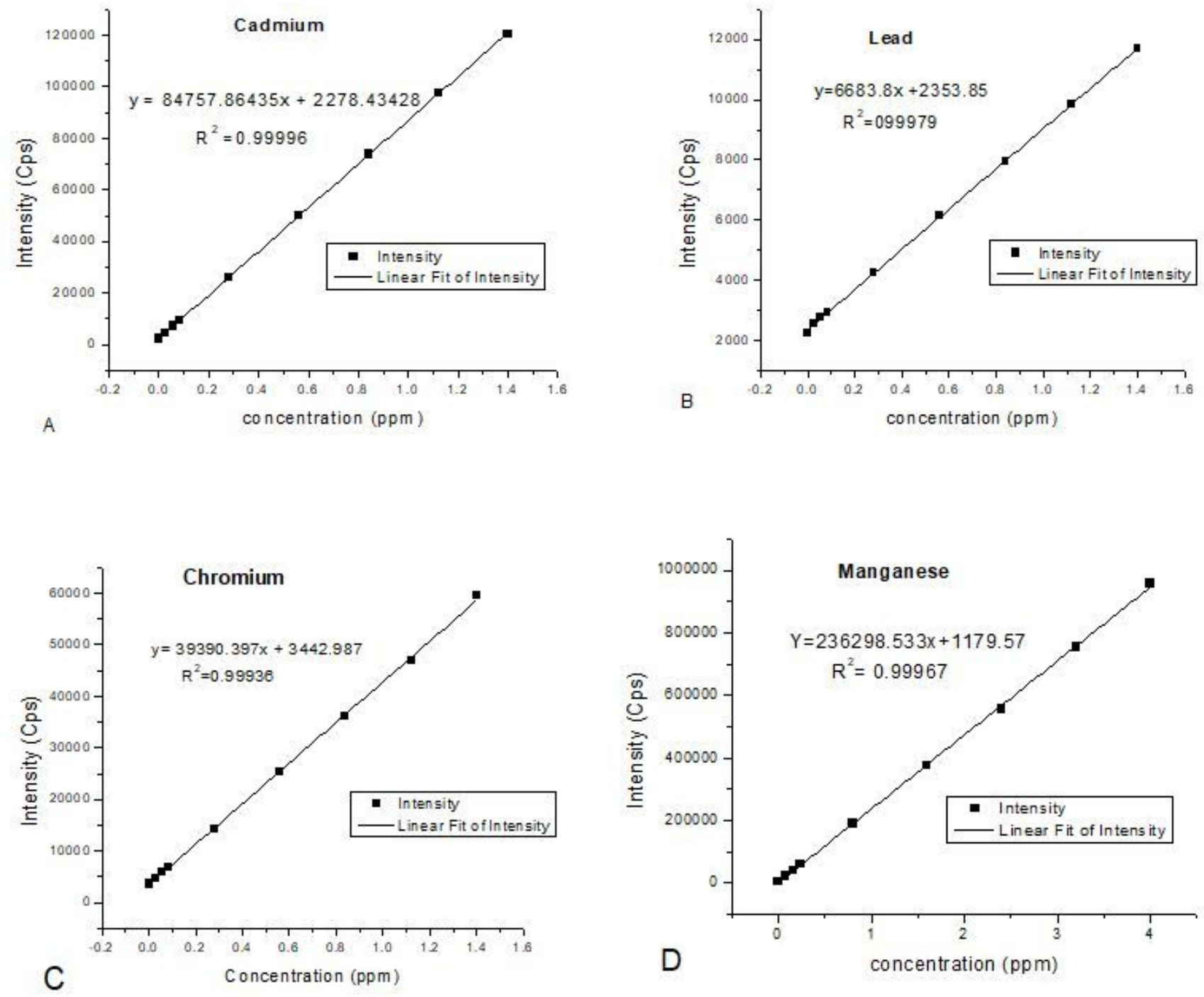

Figure 1

(A-D) Calibration standard curves of the metals for ICP-OES measurement 


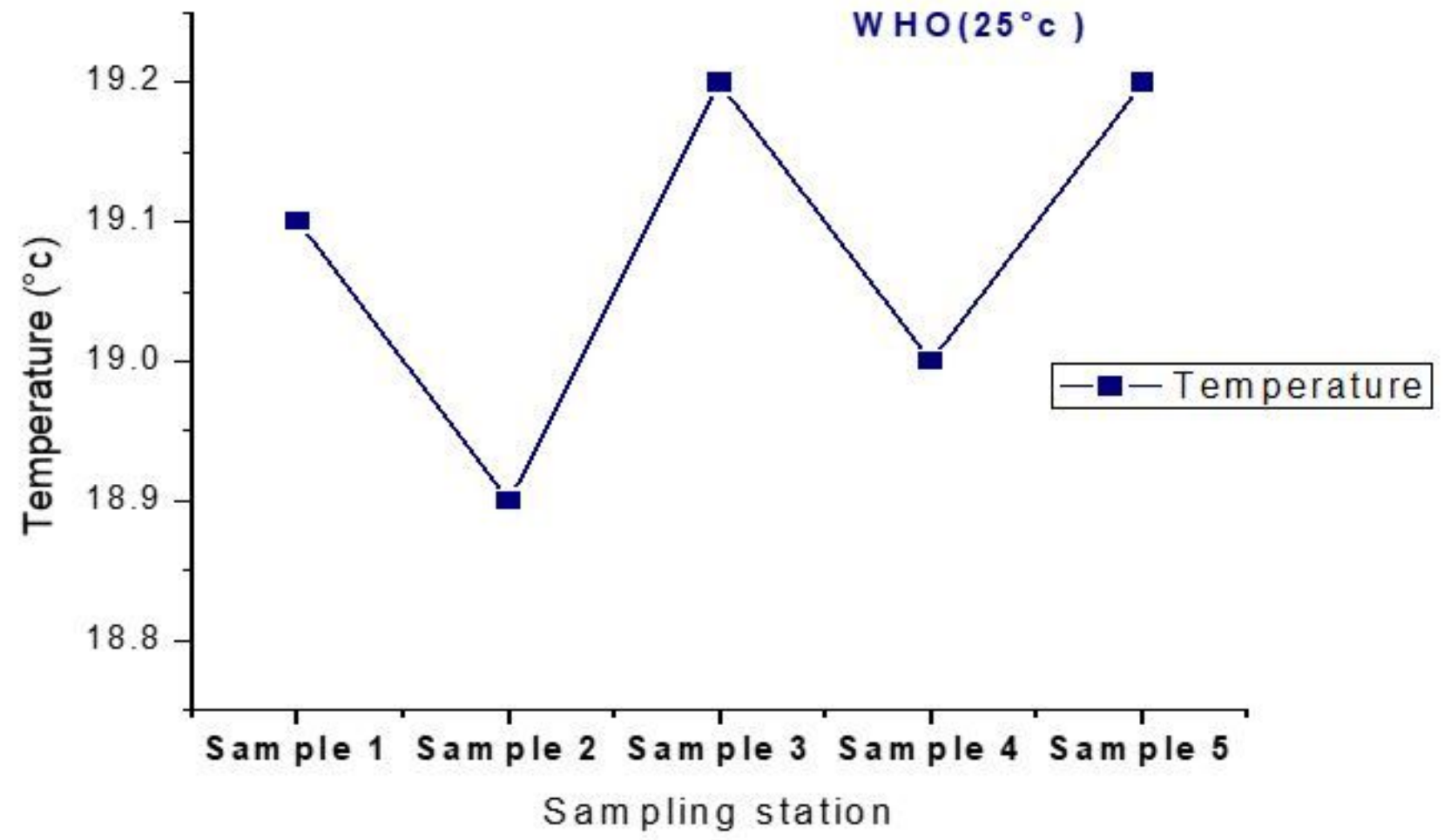

Figure 2

Graphical representation of observed temperature $\left({ }^{\circ} \mathrm{C}\right)$ values in Abzana water

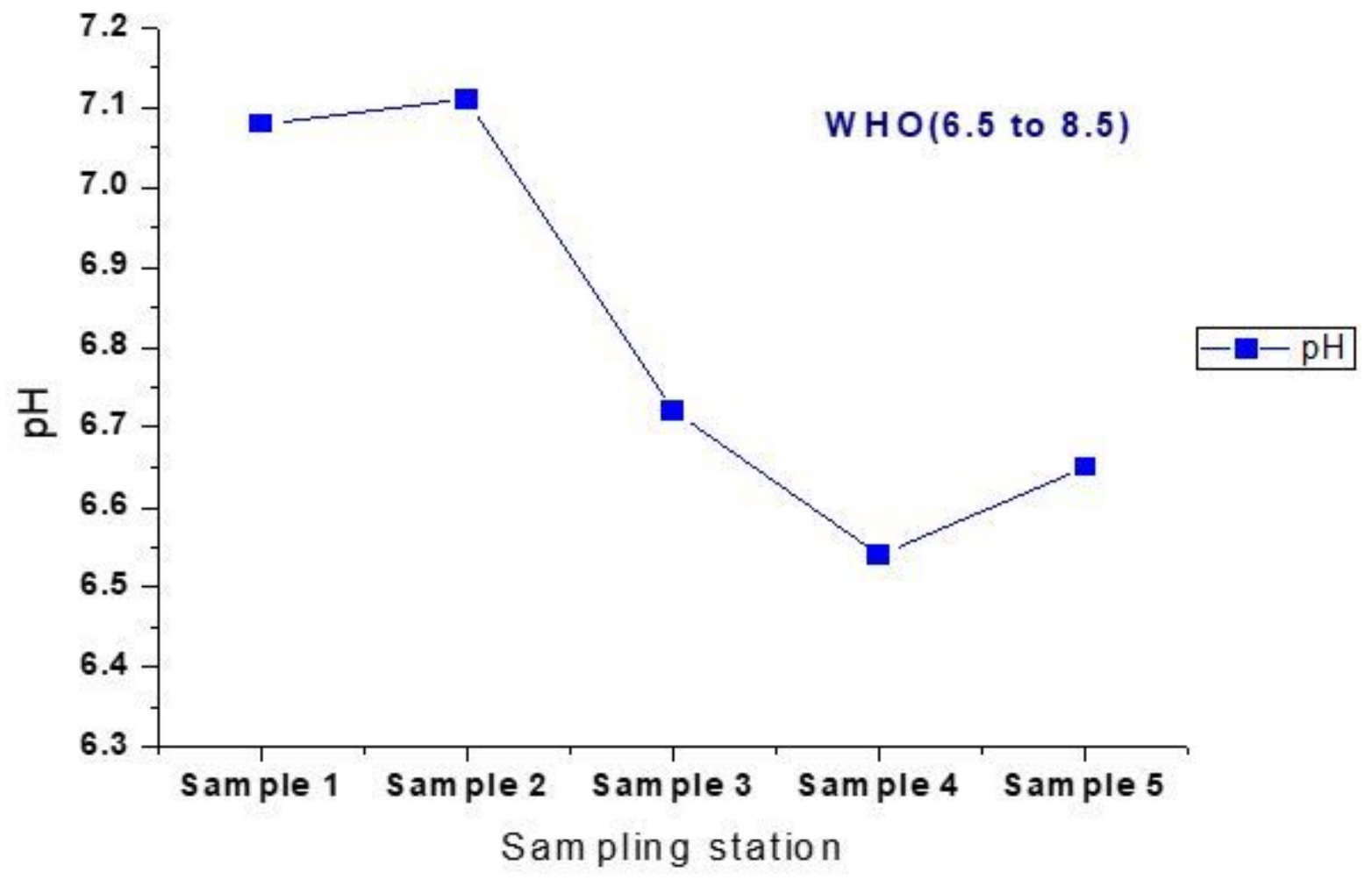


Figure 3

Graphical representation of observed values of $\mathrm{pH}$ in Abzana water

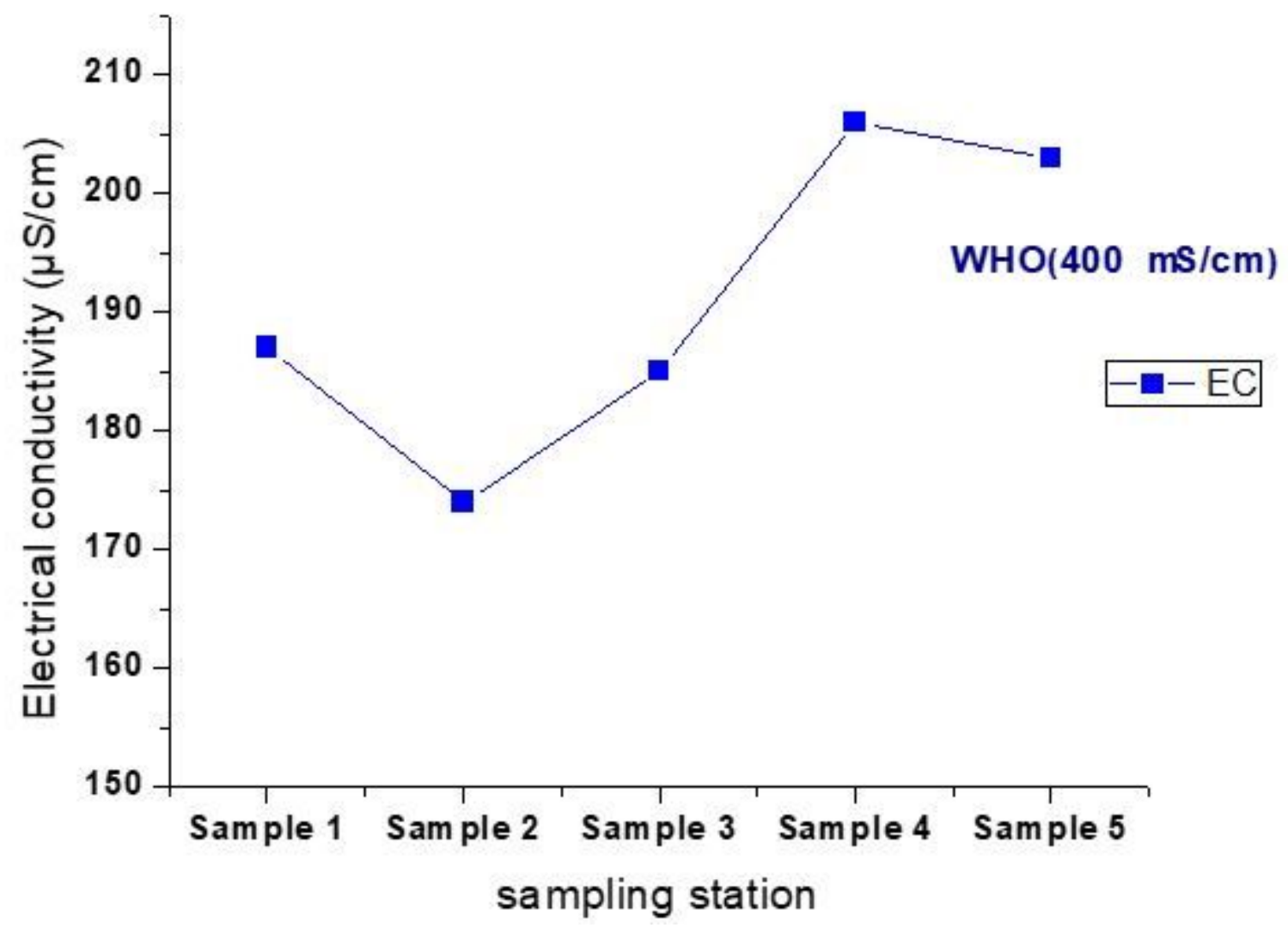

Figure 4

Graphical representation of observed values of EC in Abzana water 


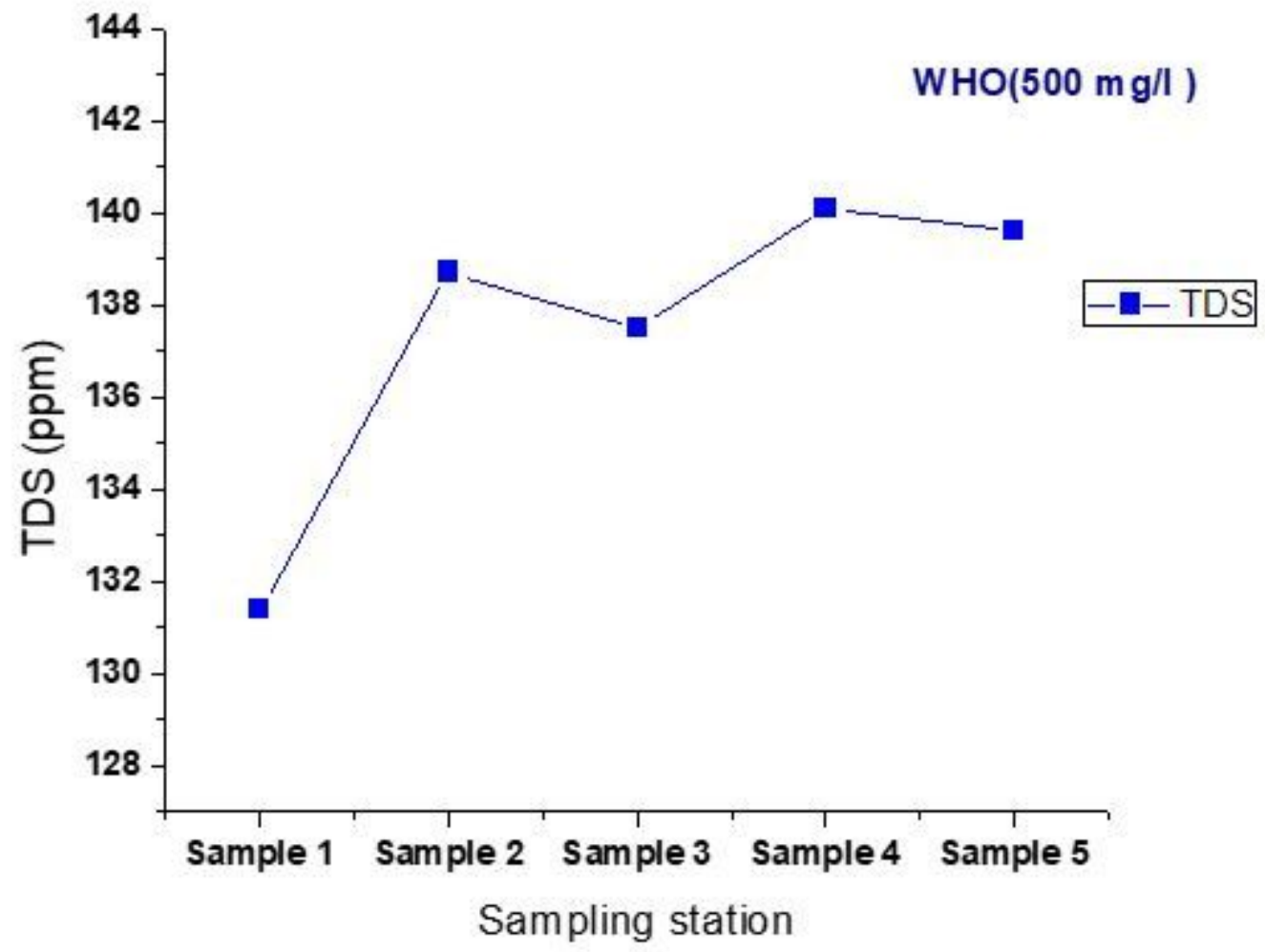

Figure 5

Graphical representation of observed values of TDS in Abzana water.

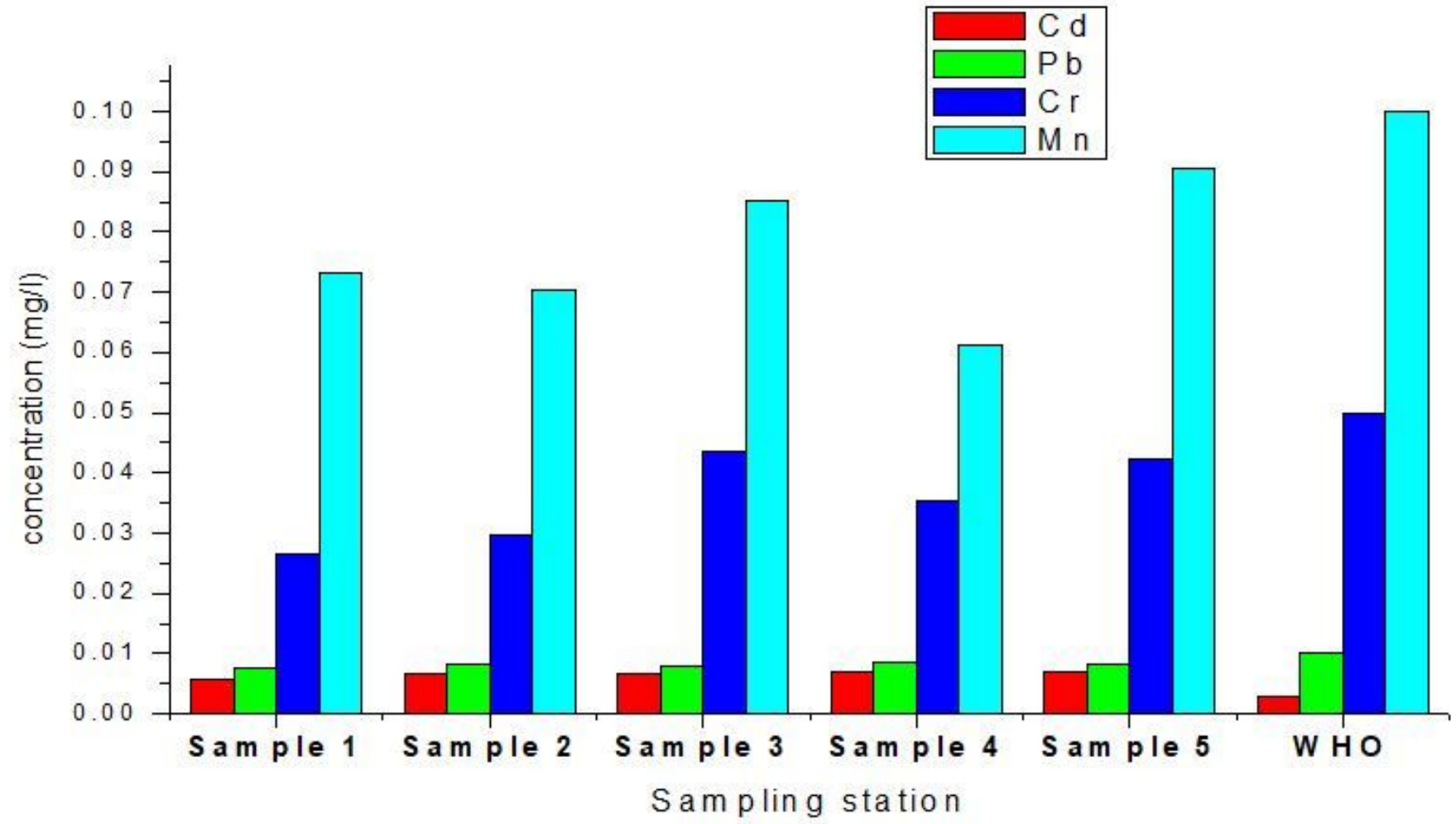

Figure 6 
Distributions of heavy metal ( $\mathrm{Cd}, \mathrm{Pb}, \mathrm{Cr}$ and $\mathrm{Mn})$ concentration in Abzana water samples and the recommended WHO value

\section{Supplementary Files}

This is a list of supplementary files associated with this preprint. Click to download.

- supplimentaryfile.docx 